\title{
Hydrophobic Waxes in Ivory Nuts Affect Surface Modification by Atmospheric Air Plasma Jet ${ }^{\dagger}$
}

\author{
Yuri Ferreira da Silva ${ }^{1, *}$, Renata Nunes Oliveira ${ }^{2}$, Renata Antoun Simão ${ }^{1}$ \\ 1 Department of Metallurgical and Materials Engineering, Federal University of Rio de Janeiro, P.O. Box: 68505, 21945- \\ 970, Rio de Janeiro, RJ, Brazil; yuri@ metalmat.ufrj.br (Y.F.S.); renata@ metalmat.ufrj.br (R.A.S.); \\ 2 Department of Materials Engineering, Federal Rural University of Rio de Janeiro, Km 7 BR 465, 23890-000, Seropédica, \\ RJ, Brazil; renatanunes.ufrrj@gmail.com (R.N.O.); \\ * Correspondence: yuri@metalmat.ufrj.br; \\ $\dagger$ Presented at Materials Chemistry and Physics (Materials Chemistry 2020) - International e-Conference
}

Received: 16.09.2020; Revised: 20.09.2020; Accepted: 24.09.2020; Published: 27.09.2020

\begin{abstract}
Ivory nuts, produced by palms from the genus Phytelephas, possess a hard and microporous endosperm with a strong resemblance to elephant ivory. The nuts sustainable appeal made them popular as eco-friendly substitutes to ivory since they promote the development of forest communities without contributing to deforestation and animal poaching. In addition, they have been commercialized as microbeads to replace microplastics in cosmetic applications. However, this material is vulnerable to deterioration by micro-organisms and insects, as they are predominantly constituted by $\beta-1,4-$ mannan, a hydrophilic polysaccharide similar to cellulose. In this context, seed endosperm was treated for $80 \mathrm{~s}$ by an atmospheric air plasma jet so as to modify its wettability, as plasma has been widely studied recently for seed disinfection and surface modification. Plasma treated samples were characterized by the water contact angle, AFM, and Raman imaging. Water contact angle results showed an increase from $(31.5 \pm 8.7)^{\circ}$ to $(78.9 \pm 5.4)^{\circ}$, indicating incorporation of hydrophobic moieties to the sample surface. In turn, AFM images demonstrate the formation of a rough and heterogeneous coating that resembles epicuticular wax layers. Furthermore, principal component analysis of Raman imaging results evidenced contributions from wax $\left(1156,1170\right.$ and $\left.1410 \mathrm{~cm}^{-1}\right)$, carbohydrates $(1020,1080$ and $\left.1106 \mathrm{~cm}^{-1}\right)$, and lignin $\left(1573,1635\right.$ and $\left.1662 \mathrm{~cm}^{-1}\right)$. These results indicate that plasma treatment promoted the migration of hydrophobic waxes to the surface and their crosslinking with fragmented cell wall material such as mannan, xylan, and lignin, promoting seed hydrophobization with no need for additional precursors or generation of side products.
\end{abstract}

Keywords: phytelephas; ivory nut; tagua; vegetable ivory; plasma jet; wettability; hydrophobic; atomic force microscopy; raman imaging; principal component analysis.

(C) 2020 by the authors. This article is an open-access article distributed under the terms and conditions of the Creative Commons Attribution (CC BY) license (https://creativecommons.org/licenses/by/4.0/).

\section{Funding}

This research was funded by CNPq (Conselho Nacional de Desenvolvimento Científico e Tecnológico) and was financed in part by the Coordenação de Aperfeiçoamento de Pessoal de Nível Superior - Brasil (CAPES) - Finance Code 001. 


\section{Acknowledgments}

The authors would like to acknowledge the infrastructure and support from the Department of Metallurgical and Materials Engineering (DMM/PEMM/COPPE) from the Federal University of Rio de Janeiro (UFRJ).

\section{Conflicts of Interest}

The authors declare no conflict of interest. The funders had no role in the design of the study; in the collection, analyses, or interpretation of data; in the writing of the manuscript, or in the decision to publish the results. 